\title{
Metastatic Seeding of Colon Adenocarcinoma Manifesting as Synchronous Breast and Chest Wall Localization: Report of a Case
}

\author{
Daniela Cabibi ${ }^{1}$, Calogero Cipolla ${ }^{2}$, Maria Rosaria Valerio $^{3}$, and Sabrina Ingrao ${ }^{1}$ \\ ${ }^{1}$ Department of Human Pathology, ${ }^{2}$ Department of Oncology, Division of General and Oncological Surgery, and ${ }^{3}$ Department of Oncology, \\ Division of Medical Oncology, University of Palermo, A.O.U. Policlinico "Paolo Giaccone”, Via del Vespro 129, 90127 Palermo, Italy
}

\begin{abstract}
Colon carcinoma rarely metastasizes to the breast and it is usually associated with a poor prognosis. Even rarer is metastatic seeding of colon cancer cells in an intramammary location after surgery. Including a primary breast malignancy in the differential diagnosis of such cases is mandatory. We report a rare case of double seeding implantation of colon adenocarcinoma inside the breast parenchyma and intercostal muscles 6 years after resection of a pulmonary metastasis from colon adenocarcinoma. The metastasis was revealed by the presence of bone metaplasia in the intercostal muscles. We discuss how negative immunostaining for estrogen receptors, progesterone receptors, and HER-2, along with the immunohistochemical pattern of cytokeratin (CK) 20+/7-/5- and CDX2-positive immunostaining, excludes a primary breast malignancy, namely, a "matrixproducing" carcinoma, from the differential diagnosis. We also present the hypothesis of a paracrine pathogenetic mechanism to explain the bone metaplasia.
\end{abstract}

Key words Bone metaplasia $\cdot$ Seeding $\cdot$ Adenocarcinoma of the colon $\cdot$ Cytokeratin-7 $\cdot$ Cytokeratin-20

\section{Introduction}

Breast metastases from colon adenocarcinoma are very rare $^{1-4}$ and may be confused with a primary neoplasm of the breast. Because the treatment and outcome of primary and secondary malignancies of the breast are completely different, an accurate diagnosis is important. The expression of estrogen receptors (ERs) and progesterone receptors (PRs) often suggests the primary breast origin of a malignancy, but certain breast carci-

Reprint requests to: C. Cipolla

Received: July 11, 2009 / Accepted: September 15, 2009 nomas are negative for these receptors. Immunohistochemical assay using the anti-cytokeratin-7 (CK7) and anti-cytokeratin-20 (CK20) antibodies has been introduced to assist in differentiating primary and metastatic neoplasias. Typical CK7/CK20 patterns are present in adenocarcinomas of different origin. In fact, most breast carcinomas show a CK7+/CK20- pattern, whereas most colon adenocarcinomas are CK7-/CK20+. ${ }^{5}$ Expression of CK5 has been reported in basal-like breast carcinomas, which are negative for ER, PR, and HER-2 expression and enclose an even rarer histotype, known as a "matrix-producing" carcinoma, showing cartilaginous and/or bone metaplasia. ${ }^{6-8}$ We report a case of breast metastatic seeding of colon cancer cells, developing into bone metaplasia, in a woman who had undergone resection of lung metastasis from colon adenocarcinoma 6 years earlier. The surgical indications for pulmonary metastasis resection were the resectability of the lung lesion, and the absence of any sign of local recurrence of the primary lesion or of extrapulmonary lesions. ${ }^{9}$

The rarity of intramammary metastatic seeding, the long interval since the lung metastasis resection, and the unusual histological picture, with bone metaplasia in one of the metastatic sites, made it difficult to differentiate the colon cancer metastasis from a primary "matrixproducing" breast carcinoma. Thus, we stress the importance of immunohistochemistry through the presentation of this case.

\section{Case Report}

A 76-year-old woman was referred to us for investigation of a mammary nodule, which had been misdiagnosed as breast ductal infiltrating carcinoma G2, based on needle core biopsy findings at another hospital. Clinically, the nodule was $1.6 \mathrm{~cm}$ in maximum diameter and located within the breast parenchyma, peripherally, between the upper and the lower external quadrant. 

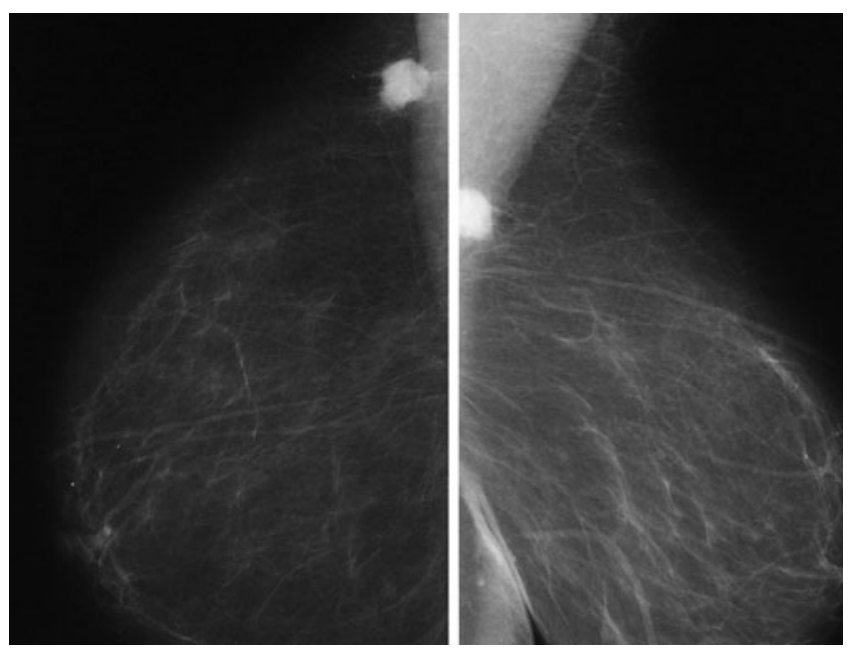

Fig. 1. Mammographic image of the tumor

Hereafter we refer to this nodule as "nodule A." A breast X-ray showed radio-opacity of the unclear margins of the nodule in the external upper segment of the right breast, not far from the chest wall (Fig. 1).

The patient reported that about 7 years previously, she had undergone a left hemicolectomy for adenocarcinoma of the descending colon, pT3 N1 M0 (TNM Stage IIIB), at another hospital, and that histopathological examination had revealed vascular invasion. Fourteen months later, a single lung metastasis from the adenocarcinoma of the colon was detected in the upper lobe of the right lung. Computed tomography (CT) scan and histological examination revealed that this mass was deeply located far from the pleural surface of the lung. Thus, the patient underwent a wedge resection of the upper lobe of the right lung, with placement of a drainage tube, which exited across the fourth intercostal space, consistent with the location of the skin scar. From the time of the second operation until the discovery of the breast nodule, no further treatment was given and the patient was not followed up.

On admission, the values of the tumor markers carcinoembryonic antigen, tissue polypeptide antigen, and carbohydrate antigens $15-3,125$, and 19-9 were within the normal range. Chest radiography, abdominal ultrasonography, and whole-body bone scintigraphy showed no lesions indicative of metastasis. Considering the age of the patient, we decided to perform an upper-external quadrantectomy of the right breast. After removing this quadrant, we palpated another nodular swelling about $3 \mathrm{~cm}$ in diameter in the chest wall below the pectoral muscles. Hereafter we refer to this nodule as "nodule B." Raising this nodule with a divaricator revealed a tumor within the fourth intercostal space, in the intercostal muscle, from which it was then isolated and removed. The patient was sent home on day 2 after an uneventful recovery.

Histological examination was performed on formalinfixed, paraffin-embedded hematoxylin-eosin-stained sections. Both nodules consisted of neoplastic, moderately differentiated gland tissue, apparently compatible with the diagnosis of ductal infiltrating carcinoma G2. No excess mucous production was observed. Interestingly, nodule B contained large areas of bone metaplasia, consisting of fully matured bone metaplastic tissue, with rows of osteoblasts along the edge of the osseous trabeculae (Fig. 2a,b). No bone metaplasia was seen in nodule A. Immunostaining was negative for ERs, PRs, and HER-2 in both nodules. Reports of colon adenocarcinoma metastatic to the lungs justified further immunohistochemical analysis with CK7, CK20, CK5, and CDX2. In both nodules, a CK20+/CK7-/CK5-/CDX2+ immunohistochemical pattern could be seen (Fig. 2c-e). Moreover, in nodule B several slender and atrophic muscle fibers, located very close to the metaplastic bone trabeculae and to the neoplastic glands, were highlighted by using anti-desmin antibody (Fig. 2f). Based on these findings, we excluded primary breast malignancy and diagnosed intestinal carcinoma metastasis.

The hypothesis of metastatic seeding of malignant cancer cells was proposed, even though 5 years had elapsed since the pulmonary wedge resection, because the site of the two nodules coincided with the path and the skin scar of the drainage tube. Histological sections of the previously resected primary colon tumor and lung metastases were revised, but no bone metaplasia was observed. The patient is still alive without further evidence of metastases after a 1.5 year follow-up.

\section{Discussion}

The seeding of malignant cancer cells along the path of the drainage tube is a rare complication of some surgical procedures and of percutaneous drainage. It is most frequently reported after percutaneous biliary drainage for pancreatic carcinoma ${ }^{10,11}$ and cholangiocarcinoma, ${ }^{12-17}$ after laparotomy resection of colorectal cancer ${ }^{18}$ and, occasionally, for carcinoma of the uterine cervix. ${ }^{19,20}$ The chest wall implantation of cancer cells at the drainage tube site has been reported after lobectomy, ${ }^{21}$ pericardiocentesis, ${ }^{22}$ and needle aspiration biopsy $^{23}$ in patients with pulmonary malignancies. According to a recent report, catheter-tract metastasis was found in $6.7 \%$ of 45 patients treated with indwelling pleural catheters for malignant pleural effusions. ${ }^{24}$ The skin is the most common site of the implantation. To our knowledge, intramammary dissemination has only ever been reported in one patient after percutaneous 



Fig. 2. a, b The intramammary nodule (a) and intercostal muscle nodule (b) both contained neoplastic, moderately differentiated gland tissue. There was no excess mucous production. Bone metaplasia was present only in $\mathbf{b}(\mathbf{a}, \mathbf{b}$ hematoxylin-eosin, $\times 200)$. c Positivity for cytokeratin-20 immunostaining $(\times 400)$. d Negativity for cytokeratin-7 immu- nostaining $(\times 400)$. e Positivity for CDX2 immunostaining $(\times 200)$. $f$ Microscopic findings of the intercostal muscle nodule. Slender and atrophic muscle fibers, close to the metaplastic bone trabeculae and to the neoplastic glands, were highlighted by the anti-desmin antibody (anti-desmin immunostaining, $\times 200)$ 
transthoracic needle aspiration biopsy of a pulmonary neoplasm. ${ }^{23}$

There are several interesting clinical and histological aspects of this case: the intramammary localization of one of the two nodules; the long interval after the lung lobectomy; and the presence of bone metaplasia, observed only in the intercostal muscle nodule but absent in the intramammary nodule and in the previously resected specimens of colon carcinoma and lung metastasis. Cartilaginous and/or bone metaplasia have been reported in the rare "matrix-producing" carcinoma, which shows negative immunostaining for ERs, PRs, and HER-2 and positive immunostaining for CK5 expression, and is included within the basal-like phenotype..$^{6-8}$ Although CK7 expression is present in most breast carcinomas, it is noteworthy that it was reported in one case of "matrix-producing" carcinoma ${ }^{25}$ and in some metaplastic spindle cell carcinomas. ${ }^{26} \mathrm{On}$ the contrary, no primary breast carcinomas have been reported to be positive for CK20 immunostaining. Finally, the positive immunostaining for CDX2, a highly sensitive and specific marker of colon carcinoma, ${ }^{27}$ along with the CK20+/CK7-/CK5- immunohistochemical pattern, made the diagnosis of a primary breast carcinoma unlikely and led us to hypothesize that the patient had double synchronous breast and chest wall metastases of colon adenocarcinoma, one of which had bone metaplasia.

Bone metaplasia is a rare phenomenon more often described in metastasis of colon carcinomas and biliary tract carcinomas. The pathogenesis is still not fully understood, but it is speculated that the extravasation of mucin may play a stimulatory role. ${ }^{28,29}$ It was suggested recently that bone metaplasia may result from the metaplasia of pluripotent stem cells into osteoblast cells induced by bone morphogenetic proteins (BMP-2, $-4,-6,-7),{ }^{30}$ among which BMP-2 may play an important paracrine role. ${ }^{31}$ In the model designed by Lee et al. ${ }^{32}$ to study the early stage of osteoblast differentiation during bone formation in muscle tissues, treatment with BMP-2 not only blocked the myogenic differentiation of $\mathrm{C} 2 \mathrm{C} 12$ pluripotent mesenchymal precursor cells but also induced osteoblast differentiation.

Heterotopic ossification in skeletal muscle metastasis from colonic adenocarcinoma has also been reported..$^{33,34}$ However, we observed no excess mucus production in our patient, so a stimulatory role of mucins could not be hypothesized. Furthermore, the presence of mature bone metaplasia next to the muscle fibers and neoplastic glands suggests a close relationship between these three elements, consistent with the hypothesis of a paracrine mechanism of osteogenesis induction in muscle pluripotent mesenchymal cells by cytokines produced by the neoplastic cells. Further experimental studies to verify this hypothesis are warranted.
Metastatic breast tumors from colon adenocarcinoma are rare and are usually indicative of disseminated disease, with a poor prognosis. ${ }^{2-4}$ However, our patient has no sign of further metastases even after 1.5 years of follow up. This suggests that a metastatic tumor to the breast from colon adenocarcinoma is unlikely, and supports the possibility of a double malignant seeding implantation after the lung metastasis resection. To our knowledge, this is the first report of a synchronous double seeding implantation metastasis along the drainage tube path in the breast parenchyma and in the intercostal muscle, with bone metaplasia. We emphasize the rarity of this case and the peculiarity of the clinical course and histological findings, highlighting the role of CK7, CK20, CK5, and CDX2 immunoassay in the differential diagnosis with a primary breast malignancy.

\section{References}

1. Ho YY, Lee WK. Metastasis to the breast from an adenocarcinoma of the colon. J Clin Ultrasound 2009;37:239-41.

2. Fernández de Bobadilla L, García Villanueva A, Collado M, de Juan A, Rojo R, Pérez J, et al. Breast metastasis of primary colon cancer. Rev Esp Enferm Dig 2004;96:415-9.

3. Yeh CN, Lin CH, Chen MF. Clinical and ultrasonographic characteristics of breast metastases from extramammary malignancies. Am Surg 2004;70:287-90.

4. Oksüzoğlu B, Abali H, Güler N, Baltali E, Ozişik Y. Metastasis to the breast from nonmammarian solid neoplasms: a report of five cases. Med Oncol 2003;20:295-300.

5. Park SY, Kim BH, Kim JH, Lee S, Kang GH. Panels of immunohistochemical markers help determine primary sites of metastatic adenocarcinoma. Arch Pathol Lab Med 2007;131:1561-7.

6. Beatty JD, Atwood M, Tickman R, Reiner M. Metaplastic breast cancer: clinical significance. Am J Surg 2006;191:657-64.

7. Ninomiya J, Oyama T, Horiguchi J, Koibuchi Y, Yoshida T, Iijima $\mathrm{K}$, et al. Two cases of breast cancer with cartilaginous and osseous metaplasia. Breast Cancer 2005;12:52-6.

8. Reis-Filho JS, Milanezi F, Steele D, Savage K, Simpson PT, Nesland JM, et al. Metaplastic breast carcinomas are basal-like tumours. Histopathology 2006;49:10-21.

9. Hotokezaka M, Jimi S, Hidaka H, Ikeda T, Uchiyama S, Nakashima $\mathrm{S}$, et al. Factors influencing outcome after surgery for stage IV colorectal cancer. Surg Today 2008;38:784-9.

10. Fiori E, Galati G, Bononi M, De Cesare A, Binda B, Ciardi A, et al. Subcutaneous metastasis of pancreatic cancer in the site of percutaneous biliary drainage. J Exp Clin Cancer Res 2003; 22:151-4.

11. Torreggiani WC, Lyburn I, Harris AA, Zwirewich CV. Seeding of pancreatic cancer along the path of a surgical drain: case report and literature review. Can Assoc Radiol J 2000;51:241-3.

12. Chapman WC, Sharp KW, Weaver F, Sawyers JL. Tumor seeding from percutaneous biliary catheters. Ann Surg 1989;209:70813 .

13. Verbeek PC, Van der Heyde MN, Ramsoekh T, Bosma A. Clinical significance of implantation metastases after surgical treatment of cholangiocarcinoma. Semin Liver Dis 1990;10:142-4.

14. Sano T, Nimura Y, Hayakawa N, Kamiya J, Kondo S, Nagino, et al. Partial hepatectomy for metastatic seeding complicating pancreatoduodenectomy. Hepatogastroenterology 1997;44:263-7.

15. Inagaki M, Yabuki H, Hashimoto M, Maguchi M, Kino S, Sawa M, et al. Metastatic seeding of bile duct carcinoma in the transhepatic catheter tract: report of a case. Surg Today 1999;29:1260-3. 
16. Shimizu Y, Yasui K, Kato T, Yamamura Y, Hirai T, Kodera Y, et al. Implantation metastasis along the percutaneous transhepatic biliary drainage sinus tract. Hepatogastroenterology 2004;51: 365-7.

17. Sakata J, Shirai Y, Wakai T, Nomura T, Sakata E, Hatakeyama K. Catheter tract implantation metastases associated with percutaneous biliary drainage for extrahepatic cholangiocarcinoma. World J Gastroenterol 2005;11:7024-7.

18. Torzilli G, Cremascoli G, Cattaneo S, Stefanini P, Olivari N. Drainsite tumour recurrence after laparotomy resection for colorectal cancer. Eur J Surg Oncol 1999;25:546-7.

19. Behtash N, Ghaemmaghami F, Yarandi F, Andalan FA, Kanafshar N. Cutaneous metastasis from carcinoma of the cervix at the drain site. Gynecol Oncol 2002;85:209-11.

20. Copas PR, Spann CO, Thoms WW, Horowitz IR. Squamous cell carcinoma of the cervix metastatic to a drain site. Gynecol Oncol 1995;56:102-4.

21. Sugi K, Nawata K, Ueda K, Kaneda Y, Nawata S, Oga A, et al. Chest wall implantation of lung cancer at the drainage tube site: report of a case. Surg Today 1997;27:666-8.

22. Quecedo E, Febrer I, Martínez-Escribano JA, Navarro-Iváñez R, Aliaga A. Tumoral seeding after pericardiocentesis in a patient with a pulmonary adenocarcinoma. J Am Acad Dermatol 1994; 31:496-7.

23. Sacchini V, Galimberti V, Marchini S, Luini A. Percutaneous transthoracic needle aspiration biopsy: a case report of implantation metastasis. Eur J Surg Oncol 1989;15:179-83.

24. Janes SM, Rahman NM, Davies RJ, Lee YC. Catheter-tract metastases associated with chronic indwelling pleural catheters. Chest 2007;131:1232-4.

25. Kaya H, Güllüoglu B, Aribal E. Myoepithelial differentiation in breast carcinoma. Tumori 2008;94:116-20.
26. Dunne B, Lee AH, Pinder SE, Bell JA, Ellis IO. An immunohistochemical study of metaplastic spindle cell carcinoma, phyllodes tumor and fibromatosis of the breast. Hum Pathol 2003;34:1009-15.

27. Werling RW, Yaziji H, Bacchi CE. Gown AM. CDX2, a highly sensitive and specific marker of adenocarcinomas of intestinal origin: an immunohistochemical survey of 476 primary and metastatic carcinomas. Am J Surg Pathol 2003;27(3):303-10.

28. Haque S, Eisen RN, West AB. Heterotopic bone formation in the gastrointestinal tract. West AB Arch Pathol Lab Med 1996;120:666-70.

29. Alper M, Akyürek N, Patiroğlu TE, Yüksel O, Belenli O. Heterotopic bone formation in two cases of colon carcinoma. Scand $\mathrm{J}$ Gastroenterol 2000;35:556-8

30. Imai N, Iwai A, Hatakeyama S, Matsuzaki K, Kitagawa Y, Kato S, et al. Expression of bone morphogenetic proteins in colon carcinoma with heterotopic ossification. Pathol Int 2001:51:643-8.

31. Komai Y, Morimoto S, Saito K, Urushibara M, Sakai K, Ikeda S. Possible involvement of bone morphogenetic protein 2 in heterotopic ossification in metastatic lesion from urothelial carcinoma of bladder. Int J Urol 2006;13:1126-8.

32. Lee KS, Kim HJ, Li QL, Chi XZ, Ueta C, Komori T, et al. Runx2 is a common target of transforming growth factor beta1 and bone morphogenetic protein 2, and cooperation between Runx2 and Smad5 induces osteoblast-specific gene expression in the pluripotent mesenchymal precursor cell line $\mathrm{C} 2 \mathrm{C} 12$. Mol Cell Biol 2000;20:8783-92.

33. Naik VR, Jaafar H, Mutum SS. Heterotopic ossification in skeletal muscle metastasis from colonic adenocarcinoma: a case report. Malays J Pathol 2005;27:119-21.

34. Yoshikawa H, Kameyama M, Ueda T, Kudawara I, Nakanishi K. Ossifying intramuscular metastasis from colon cancer: report of a case. Dis Colon Rectum 1999;42:1225-7. 